“This document is the unedited Author's version of a Submitted Work that was subsequently accepted for publication in Journal of Physical Chemistry A 2016, 120 (6), pp 903-910, copyright (C) American Chemical Society after peer review. To access the final edited and published work see DOI:

10.1021/acs.jpca.5b09657.”

\title{
Formation of Negative Ions upon Dissociative Electron Attachment to the Astrochemically Relevant Molecule Aminoacetonitrile
}

Andrzej Pelc ${ }^{1, *}$, Stefan E. Huber ${ }^{2}$, Carolina Matias ${ }^{2}$, Zbigniew Czupyt ${ }^{3}$, and Stephan Denifl ${ }^{2, *}$

${ }^{1}$ Marie Curie-Sklodowska University, Institute of Physics, Mass Spectrometry Laboratory, Pl.

M. C.-Sklodowskiej 1, 20-031 Lublin, Poland

${ }^{2}$ Institut für Ionenphysik und Angewandte Physik, Leopold Franzens Universität Innsbruck, Technikerstr. 25, 6020 Innsbruck, Austria

${ }^{3}$ Ion Microprobe Facility Micro-area Analysis Laboratory, Polish Geological Institute National Research Institute, Rakowiecka 4, 00-975 Warszawa, Poland

*corresponding authors e-mails: Andrzej.Pelc@poczta.umcs.lublin.pl, Stephan.Denifl@uibk.ac.at

Keywords: aminoacetonitrile, $\mathrm{NH}_{2} \mathrm{CH}_{2} \mathrm{CN}$, dissociative electron attachment, negative ions, astrochemistry, prebiotical compound, $\mathrm{CN}^{-}$ 


\section{Abstract}

Aminoacetonitrile $\left(\mathrm{NH}_{2} \mathrm{CH}_{2} \mathrm{CN} ; \mathrm{AAN}\right)$ is a molecule relevant for interstellar chemistry and the chemical evolution of life. It is a very important molecule in the Strecker diagram explaining the formation of amino acids. In the present investigation, dissociative electron attachment to $\mathrm{NH}_{2} \mathrm{CN}$ was studied in a crossed electron - molecular beams experiment in the electron energy range from about $0 \mathrm{eV}$ to $17 \mathrm{eV}$. In this electron energy range, the following six anionic species were detected: $\mathrm{C}_{2} \mathrm{H}_{3} \mathrm{~N}_{2}^{-}, \mathrm{C}_{2} \mathrm{H}_{2} \mathrm{~N}_{2}^{-}, \mathrm{C}_{2} \mathrm{H}_{2} \mathrm{~N}^{-}, \mathrm{C}_{2} \mathrm{HN}^{-}$, $\mathrm{CN}^{-}$, and $\mathrm{NH}_{2}^{-}$. Possible reaction channels for all the measured negative ions are discussed and the experimental results are compared with calculated thermochemical thresholds of the observed anions. Similarly to other nitrile and aminonitrile compounds, the main anions detected were the negatively charged nitrile group, the dehydrogenated parent molecule and the amino group. No parent anion was observed. Low anion yields were observed indicating that AAN is less prone to electron capture. Therefore, AAN can be considered to exhibit a relatively long life time under typical conditions in outer space.

\section{INTRODUCTION}

The interest in studies on effects of the interaction between low energy electrons with biologically relevant molecules is steadily growing over the last years. ${ }^{1-4}$ In this work, we report a study of electron attachment to aminoacetonitrile, $\mathrm{NH}_{2} \mathrm{CH}_{2} \mathrm{CN}$, (denoted as $\mathrm{AAN}$ in the following), which is also referred to as cyanomethylamine or glycinenitrile in the literature. Recently, we studied the negative ion formation by the dissociative electron attachment to cyanamide. ${ }^{5}$ Cyanamide as well as AAN are representatives of a biologically relevant and very important group of aminonitriles. These compounds contain two significant organic groups, namely the amino $\left(\mathrm{NH}_{2}\right)$ and cyano $(\mathrm{CN})$ groups. The former is a common 
component of biomolecules like amino acids or proteins. In the case of AAN, additionally the methylene $\left(\mathrm{CH}_{2}\right)$ bridge is connecting the two groups mentioned. Therefore, $\mathrm{NH}_{2} \mathrm{CH}_{2} \mathrm{CN}$ could also serve as a model molecule for more complex species with biological relevance. Hence, the results of our study are expected to contain information that may be transferable to these bigger biomolecules comprising the same functional groups.

AAN is an important molecule in astrophysics. It was observed in many astrophysical objects like gas clouds of the interstellar medium (ISM), e.g., Sagittarius B2, ${ }^{6}$ and atmospheres like those of the moon $\operatorname{Titan}^{7}$ where it is believed to be synthetized by heterogeneous chemistry. Among the various aminonitriles, AAN is of particular interest as it is one of the central molecules in the model route of amino acid synthesis. ${ }^{6,8}$ The first attempt to understand the pathways of AAN formation came from Strecker in $1854 .^{9}$ The proposed series of reactions leading to the formation of AAN is called Strecker synthesis, which finally aims to explain the amino acid generation. Strecker proposed that the AAN could be formed in a series of the following reactions: (i) a reaction between aldehyde and ammonia in a liquid water environment in order to form the imine, (ii) a reaction between imine and hydrogen cyanide leading to the formation of AAN.

There were also attempts to estimate the age of the interstellar clouds from the consecutive addition of HCN (an abundant molecule in the ISM) to AAN. The age of an interstellar cloud might then be revealed by the time required for the growth of the longest observed chain in a molecular sequence. ${ }^{10}$

Danger et al. ${ }^{6,11}$ showed that formation of AAN from the thermal processing of ices containing methanimine, ammonia and hydrogen cyanide under conditions alike those in the ISM is possible. Moreover, Belloche et al. ${ }^{12}$ showed that AAN may be formed by cyanogen hydrogenation or photochemically under astrophysical conditions from nitrile and ammonia mixtures. The subsequent hydrolysis of aminonitriles may lead then to amino acid formation. 
Overall, many experiments on AAN formation were conducted at different, also astrophysical-like conditions, which confirmed that nitriles could promote the formation of amino acids. ${ }^{6,11-13}$ This is of special importance as earlier studies showed that AAN and other nitriles have much longer life times under outer space conditions than organic acids. The halflife for photodestruction of AAN is about 1330 years. ${ }^{14}$

By the reasons mentioned so far it is very interesting and important to study those mechanisms by which aminoacetonitrile may be dissociated through the interaction with a surface, ions, photons and like in the present studies, electrons. The motivation for investigations on the electron - aminoacetonitrile interaction is also directly related to processes in the interstellar medium (ISM) and to elementary steps in biological material, e.g. what happens with the molecule under irradiation.

Moreover, AAN as biologically relevant molecule has also some implication for living organisms. For example AAN was used as the inhibitor of glycine oxidation ${ }^{15-17}$ in the study of the involvement of the different electron transport paths in mitochondria. Therefore any investigation of the electron - AAN molecule interaction may help with the understanding of the processes proceeding in the cells of any living organisms. In these studies again the connection between the AAN and glycine is mentioned. The AAN and its derivatives are also of interest as structural elements for drug design. ${ }^{18}$

Although AAN seems to be an essential compound in many aspects, data rarely exist on the electron impact leading to the formation of positive ions. ${ }^{19}$ Using a residual gas analyser quadrupole mass spectrometer, the vapour of AAN, desorbing from an icy surface at a temperature of $200 \mathrm{~K}$, was ionized by an electron beam at the electron energy of $70 \mathrm{eV}$. In the $\mathrm{m} / \mathrm{z}$ (mass/charge) range from 20 to 60 , three major groups of ions were observed in the obtained mass spectrum. These $\mathrm{m} / \mathrm{z}$ regions were 25 to 31,38 to 41 and 52 to 57 . The most abundant ions at $\mathrm{m} / \mathrm{z}=28,29,55,56$ (corresponding to the parent ion: $\mathrm{NH}_{2} \mathrm{CH}_{2} \mathrm{CN}^{+}$) and 27 
were detected. A similar electron impact ionization mass spectrum (with the mentioned three relevant $\mathrm{m} / \mathrm{z}$ regions) is also obtainable from the NIST web page. ${ }^{20}$ However, significant differences exist in the ion current intensities of the NIST data and the above mentioned study, ${ }^{19}$ although the same ionization method was applied in both of them. In the NIST data, there are only two major peaks corresponding to the AAN parent ion $(\mathrm{m} / \mathrm{z} 56)$ and the fragment at $\mathrm{m} / \mathrm{z}=55$ resulting from the loss of $\mathrm{H}$ atom from AAN; the latter ion has higher intensity.

In the low electron energy range $(<15 \mathrm{eV})$, electron attachment is an important process, which may lead to destruction of a molecule via dissociative electron attachment (DEA). To the best of our knowledge, there is no data available regarding the formation of negative ions by electron attachment to AAN. This additionally encouraged us to perform studies of low energy electron attachment and to determine ion efficiency curves as well as resonance energies for the most abundant fragment anions formed in free electron capture by AAN.

\section{EXPERIMENTAL}

The experiments were carried out using an established experimental setup in the Institute of Ion Physics and Applied Physics at the University of Innsbruck. The electron attachment spectrometer used in the present studies comprises a molecular beam source, a Nier type ion source and a double focussing mass spectrometer with combined magnetic and electric sector fields with a pulse counting system for detecting the ionic products. This apparatus has been described in detail previously. ${ }^{21}$ Briefly, AAN, being liquid at room temperature, was first introduced to the inlet system of the mass spectrometer. As the vapour pressure of AAN at room temperature is high enough, evaporated AAN molecules were admitted through a copper capillary of $1 \mathrm{~mm} \mathrm{I.D.} \mathrm{to} \mathrm{the} \mathrm{ion} \mathrm{source.} \mathrm{At} \mathrm{this} \mathrm{sample}$ 
temperature the pressure in the main vacuum chamber of the mass spectrometer was about $10^{-}$ ${ }^{6}$ mbar ensuring collision-free conditions. In the ion source, the AAN molecular beam was crossed with the electron beam. The electron current was set to $10 \mu \mathrm{A}$ and regulated to this value above the electron energy of about $\sim 2 \mathrm{eV}$. The anions generated by the electron attachment process were extracted by electrostatic fields to the mass filter, where they were analysed and detected by a channeltron type secondary electron multiplier. The $\mathrm{NH}_{2} \mathrm{CH}_{2} \mathrm{CN}$ sample of 98\% purity was purchased from Sigma Aldrich, Vienna, Austria.

In order to determine the energy spread of the electron beam and to calibrate the electron energy scale, the well-known cross sections for the formation of $\mathrm{SF}_{6}^{-}, \mathrm{F}_{2}{ }^{-}$, and $\mathrm{F}^{-}$by electron attachment to $\mathrm{SF}_{6}$ were used. ${ }^{22}$ The resonances of all three anions were used for calibration of the electron energy scale whereas the $\sim 0 \mathrm{eV}$ resonance of $\mathrm{SF}_{6}^{-}$was used to determine the electron energy spread (the apparent FWHM - full width at half maximum - represents the energy resolution of the electron beam). In the present experiments the FWHM was $0.8 \mathrm{eV}$. The accuracy of peak maxima reported here is about $\pm 0.2 \mathrm{eV}$. Moreover, we note that the onsets of resonances are shifted downwards due the beam energy spread. Therefore we estimated the experimental threshold by a linear fit of the left tail of the resonance and extrapolation to zero ion yield. We estimate the accuracy of the thresholds to $\pm 0.4 \mathrm{eV}$.

\section{QUANTUM CHEMICAL CALCULATIONS}

To complement and support the analysis and interpretation of the experimental results, we used the well-established high-level extrapolation scheme $\mathrm{W} 1 \mathrm{BD}^{25}$ for the calculation of (adiabatic) electron affinities (EA) and thermochemical reaction thresholds (TRT). W1BD 25 is considered to yield very high accuracy and achieves a mean absolute deviation from experiment of $0.48 \mathrm{kcal} / \mathrm{mol}$ for a variety of properties (like atomization energies, electron 
and proton affinities, etc.) assembled in the G2/97 26,27 test set. This extrapolation scheme was used also in the mentioned previous study on cyanamide. ${ }^{5}$ The reaction thresholds have been obtained as the difference between all ground state energies of the reaction products (anionic and neutral fragments) and reactants (i.e., here, the parent molecule). The computed electron affinities are summarized in Table 1. In the following section, the derived reaction thresholds $\Delta \mathrm{E}$ are mentioned for the specified reaction channels. All quantum chemical calculations have been carried out using the Gaussian 09 software. ${ }^{28}$

Table 1. Adiabatic electron affinities (EA) for the $\mathrm{NH}_{2} \mathrm{CH}_{2} \mathrm{CN}$ molecule and relevant neutral fragments as obtained with the W1BD extrapolation scheme.

\begin{tabular}{|c|c|c|}
\hline $\begin{array}{c}\text { Electron affinities } \\
\text { for } \\
\text { molecules/atoms }\end{array}$ & W1BD [eV] & NIST [eV] [16] \\
\hline $\mathrm{NH}_{2} \mathrm{CH}_{2} \mathrm{CN}$ & -0.85 & \\
\hline $\mathrm{NHCH}_{2} \mathrm{CN}$ & 1.55 & \\
\hline $\mathrm{NH}_{2} \mathrm{CHCN}$ & 0.95 & \\
\hline $\mathrm{NH}_{2} \mathrm{CCN}$ & 0.59 & \\
\hline $\mathrm{NCH}_{2} \mathrm{CN}$ & 0.34 & \\
\hline $\mathrm{NHCHCN}^{\mathrm{NH}_{2} \mathrm{CH}} 2 \mathrm{C}$ & 0.38 & \\
\hline $\mathrm{NH}_{2} \mathrm{CH}$ & 0.93 & \\
\hline $\mathrm{NH}_{2} \mathrm{CN}$ & -0.63 & \\
\hline $\mathrm{CH}_{2} \mathrm{CN}$ & -0.80 & \\
\hline $\mathrm{CHCN}$ & 1.55 & \\
\hline $\mathrm{CH}_{3} \mathrm{CN}$ & 2.55 & \\
\hline $\mathrm{N}_{2} \mathrm{H}_{4}$ & -1.14 & \\
\hline $\mathrm{C}_{2} \mathrm{H}_{2}$ & -1.55 & \\
\hline & & \\
\hline & -1.22 & \\
\hline & & \\
\hline & & \\
\hline & & \\
\hline & & \\
\hline
\end{tabular}




\begin{tabular}{|c|c|c|}
\hline $\mathrm{C}_{2} \mathrm{H}_{4}$ & -1.69 & \\
\hline $\mathrm{NH}_{3}$ & -1.35 & \\
\hline $\mathrm{NH}_{2}$ & 0.75 & 0.77 \\
\hline $\mathrm{NH}$ & 0.34 & 0.37 \\
\hline $\mathrm{N}$ & -0.18 & \\
\hline $\mathrm{CN}$ & 3.90 & 3.86 \\
\hline $\mathrm{CH}_{4}$ & -1.28 & \\
\hline $\mathrm{CH}_{3}$ & 0.029 & 0.08 \\
\hline $\mathrm{CH}_{2}$ & 0.64 & 0.65 \\
\hline $\mathrm{CH}$ & 1.21 & 1.24 \\
\hline $\mathrm{C}$ & 1.25 & 1.26 \\
\hline $\mathrm{H}$ & 0.29 & 0.75 \\
\hline
\end{tabular}

\section{RESULTS AND DISCUSSION}

Electron attachment to AAN is a purely dissociative process yielding production of six anionic fragments at m/z of $55\left(\mathrm{C}_{2} \mathrm{H}_{3} \mathrm{~N}_{2}^{-}\right), 54\left(\mathrm{C}_{2} \mathrm{H}_{2} \mathrm{~N}_{2}^{-}\right), 40\left(\mathrm{C}_{2} \mathrm{H}_{2} \mathrm{~N}^{-}\right), 39\left(\mathrm{C}_{2} \mathrm{HN}^{-}\right), 26\left(\mathrm{CN}^{-}\right)$, $16\left(\mathrm{NH}_{2}{ }^{-}\right)$. The possibility of a stable negatively charged AAN parent ion was previously predicted in calculations (MP2/TZVP), in which the EA value of $0.07 \mathrm{eV}$ for the AAN molecule was obtained. ${ }^{29}$ In our experimental studies the parent anion $\mathrm{NH}_{2} \mathrm{CH}_{2} \mathrm{CN}^{-}$was not observed within the detection limit of the apparatus and also the W1BD calculations result in a negative adiabatic EA value for AAN of $-0.85 \mathrm{eV}$. Due to this discrepancy between the results of our calculations and the ones from the earlier study,${ }^{29}$ we repeated the calculations at the MP2/TZVP level of theory. We obtained the same geometries of the neutral AAN molecules as well as the anion. However, for the adiabatic EA we obtained $-1.90 \mathrm{eV}$ in line with the negative adiabatic EA obtained using W1BD. 
In Figure 1 the anion yield curves for all observed negatively charged fragments in the electron energy range of about 0 up to $17 \mathrm{eV}$ are presented. The intensities are given in arbitrary but reproducible units, i.e. the ion signals for all anions are comparable. Table 2 summarizes the present results concerning the resonance peak positions. In the following paragraphs we will discuss in detail possible production mechanisms for all fragment anions which have been detected.

Table 2. Peak positions of resonances observed in the ion yield of fragment anions obtained in dissociative electron attachment to $\mathrm{NH}_{2} \mathrm{CH}_{2} \mathrm{CN}$.

\begin{tabular}{|l|l|}
\hline Ion & $\begin{array}{l}\text { Observed resonance maxima in } \mathrm{eV} \\
\text { (uncertainty } \pm 0.2 \mathrm{eV} \text { ) }\end{array}$ \\
\hline $\mathrm{CN}^{-}$ & 1.9 and 5.6 \\
\hline $\mathrm{NH}_{2}{ }^{-}$ & 5.6 and $\sim 9.4$ \\
\hline $\mathrm{C}_{2} \mathrm{H}_{3} \mathrm{~N}_{2}$ & 3.2 and 5.2 \\
\hline $\mathrm{C}_{2} \mathrm{H}_{2} \mathrm{~N}^{-}$ & $\sim 2,2.9,5.4,10.8, \sim 15$ \\
\hline $\mathrm{C}_{2} \mathrm{H}_{2} \mathrm{~N}_{2}^{-}$ & 2.5 and 5.6 \\
\hline $\mathrm{C}_{2} \mathrm{HN}^{-}$ & $1.3,2.4,5.6,8.3,10.8$ \\
\hline
\end{tabular}


Figure 1. Fragment anions observed in DEA to $\mathrm{NH}_{2} \mathrm{CH}_{2} \mathrm{CN}$.

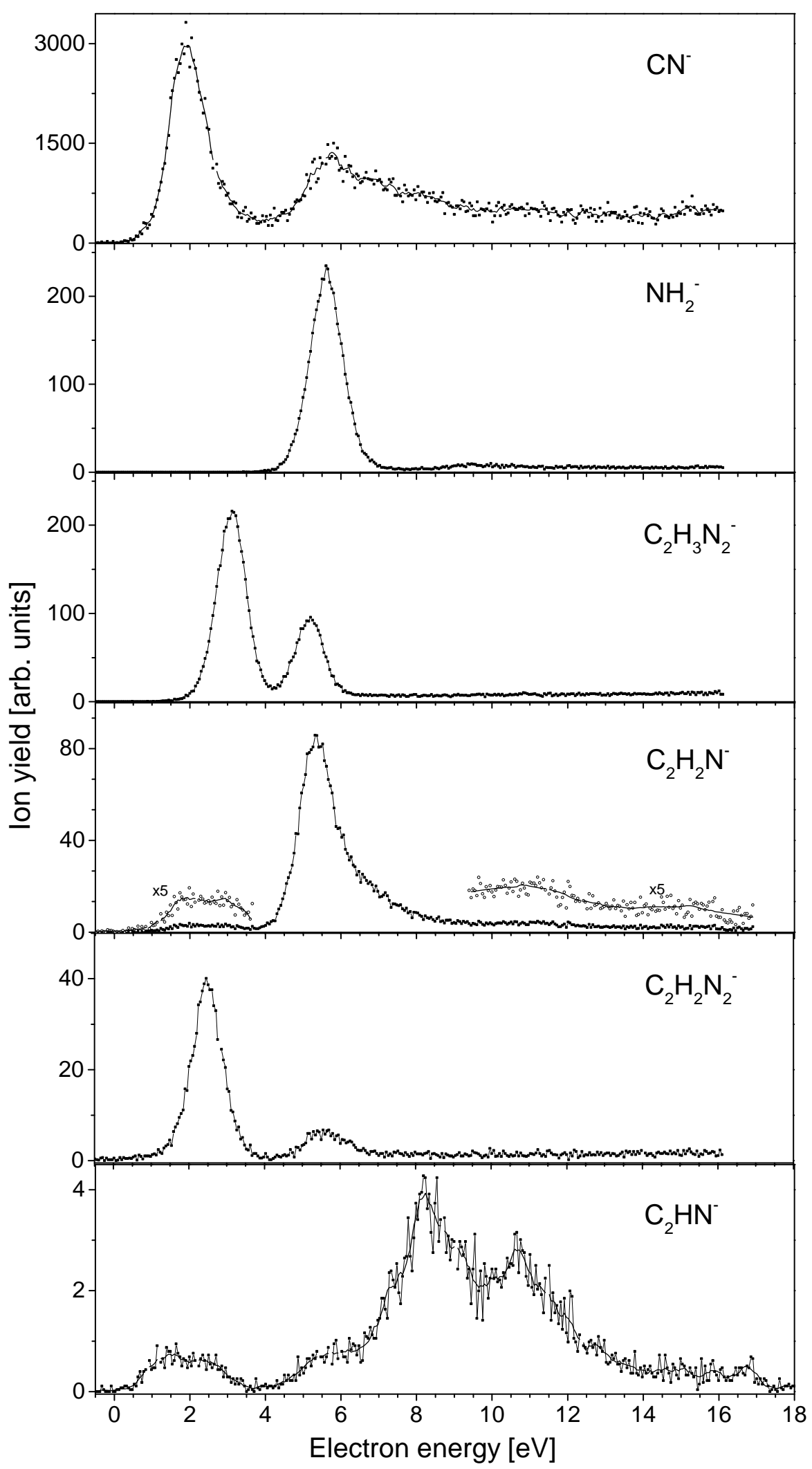


The observation of the $\mathrm{CN}^{-}$anion in DEA to AAN is of special importance. This negative ion is the smallest molecular anion detected in space. ${ }^{30}$ Hence, it is important to know the possible pathways of $\mathrm{CN}^{-}$formation. Related to this issue its generation from AAN may have some implications to the understanding of $\mathrm{CN}^{-}$occurrence in the ISM, especially if we take into account that, according to our data, the $\mathrm{CN}^{-}$anion is the most efficiently formed anion in DEA to AAN. This result is in line with our previous studies of DEA to acetonitrile and cyanamide ${ }^{5,31}$ with the $\mathrm{CN}^{-}$as the most intensively generated anion. We also note that this is further in agreement with other studies of electron attachment to different nitrile molecules $\left(\mathrm{C}_{2} \mathrm{H}_{3} \mathrm{CN}, \mathrm{C}_{6} \mathrm{H}_{5} \mathrm{CN}\right.$ and $\left.\mathrm{CF}_{3} \mathrm{CN}\right),{ }^{32,33}$ where the $\mathrm{CN}^{-}$anion was the major or one of the major ions observed. However, despite of the high electron affinity of CN (3.90 eV - see Table I), the ion counting rates of $\mathrm{CN}^{-}$in the DEA to AAN are rather low compared to the halogen anions formed by DEA to halogenated molecules. It is also worth to add here, that in the $\mathrm{CN}^{-}$ ion yield no resonances at very low energies $(\sim 0 \mathrm{eV})$ are present as in the case of halogenated molecules. Using ab initio calculations, this situation has been explained for previously investigated nitrile molecules by considering their molecular orbital structures and energies. ${ }^{33}$ The highest occupied molecular orbital of radical anions of the nitriles is $\pi^{*}$ antibonding with virtually all the additional charge localized at the nitrile group, resulting in a reduction of the $\mathrm{C} \equiv \mathrm{N}$ bond dissociation energy. The $\mathrm{CN}^{-}$ion generation is hence associated with the energy transfer from the $\mathrm{C} \equiv \mathrm{N}$ bond to $\mathrm{R}-\mathrm{CN}$ bond, where dissociation into $\mathrm{CN}^{-}$and the radical $\mathrm{R}$ in their electronic ground state is symmetry forbidden. For that reason it can only occur through pre-dissociation of the parent anion, and thus the cross section for formation of $\mathrm{CN}^{-}$is relatively low considering the high electron affinity value of $\mathrm{CN}$. The calculations of vibrational frequencies ${ }^{34,35}$ for $\mathrm{AAN}$ also correspond to the above assumption of a 
predissociation process in the temporary negative ion. These indicate that the $\mathrm{C}-\mathrm{C}$ bond stretching mode is most probably involved in the excitation of intense oscillations in the AAN molecule case, promoting also this bond disruption. The latter will lead to the formation of $\mathrm{CN}$ and $\mathrm{NH}_{2} \mathrm{CH}_{2}$ fragments or in the present case to one fragment in the anionic form depending on the particular EA. The measured low $\mathrm{CN}^{-}$yields are in line with the assumption of a required predissociation process.

In the present study the $\mathrm{CN}^{-}$ion is formed at two major resonance electron energies peaking at $1.9 \mathrm{eV}$ and $5.6 \mathrm{eV} .14$ possible reactions exist leading to the formation of the $\mathrm{CN}^{-}$ anion. These DEA channels together with the calculated reaction energy thresholds $(\Delta \mathrm{E})$ are:

$$
\begin{array}{ll}
\mathrm{NH}_{2} \mathrm{CH}_{2} \mathrm{CN}+\mathrm{e} \rightarrow \mathrm{CN}^{-}+\mathrm{NH}_{2} \mathrm{CH}_{2}, & (\Delta \mathrm{E}=0.99 \mathrm{eV}) \\
\mathrm{NH}_{2} \mathrm{CH}_{2} \mathrm{CN}+\mathrm{e} \rightarrow \mathrm{CN}^{-}+\mathrm{NHCH}_{3}, & (\Delta \mathrm{E}=1.21 \mathrm{eV}) \\
\mathrm{NH}_{2} \mathrm{CH}_{2} \mathrm{CN}+\mathrm{e} \rightarrow \mathrm{CN}^{-}+\mathrm{N}+\mathrm{CH}_{4}, & (\Delta \mathrm{E}=3.54 \mathrm{eV}) \\
\mathrm{NH}_{2} \mathrm{CH}_{2} \mathrm{CN}+\mathrm{e} \rightarrow \mathrm{CN}^{-}+\mathrm{NH}+\mathrm{CH}_{3}, & (\Delta \mathrm{E}=4.67 \mathrm{eV}) \\
\mathrm{NH}_{2} \mathrm{CH}_{2} \mathrm{CN}+\mathrm{e} \rightarrow \mathrm{CN}^{-}+\mathrm{NH}_{3}+\mathrm{CH}, & (\Delta \mathrm{E}=5.13 \mathrm{eV}) \\
\mathrm{NH}_{2} \mathrm{CH}_{2} \mathrm{CN}+\mathrm{e} \rightarrow \mathrm{CN}^{-}+\mathrm{NH}_{2}+\mathrm{CH}_{2}, & (\Delta \mathrm{E}=5.41 \mathrm{eV}) \\
\mathrm{NH}_{2} \mathrm{CH}_{2} \mathrm{CN}+\mathrm{e} \rightarrow \mathrm{CN}^{-}+\mathrm{NH}_{2}+\mathrm{C}+\mathrm{H}_{2}, & (\Delta \mathrm{E}=7.52 \mathrm{eV}) \\
\mathrm{NH}_{2} \mathrm{CH}_{2} \mathrm{CN}+\mathrm{e} \rightarrow \mathrm{CN}^{-}+\mathrm{N}+\mathrm{CH}_{3}+\mathrm{H}, & (\Delta \mathrm{E}=8.09 \mathrm{eV}) \\
\mathrm{NH}_{2} \mathrm{CH}_{2} \mathrm{CN}+\mathrm{e} \rightarrow \mathrm{CN}^{-}+\mathrm{N}+\mathrm{CH}_{2}+\mathrm{H}_{2}, & (\Delta \mathrm{E}=8.38 \mathrm{eV}) \\
\mathrm{NH}_{2} \mathrm{CH}_{2} \mathrm{CN}+\mathrm{e} \rightarrow \mathrm{CN}^{-}+\mathrm{NH}_{3}+\mathrm{C}+\mathrm{H}, & (\Delta \mathrm{E}=8.62 \mathrm{eV}) \\
\mathrm{NH}_{2} \mathrm{CH}_{2} \mathrm{CN}+\mathrm{e} \rightarrow \mathrm{CN}^{-}+\mathrm{N}+\mathrm{C}+2 \mathrm{H}_{2}, & (\Delta \mathrm{E}=11.74 \mathrm{eV}) \\
\mathrm{NH}_{2} \mathrm{CH}_{2} \mathrm{CN}+\mathrm{e} \rightarrow \mathrm{CN}^{-}+\mathrm{NH}_{2}+\mathrm{C}+2 \mathrm{H}, & (\Delta \mathrm{E}=12.02 \mathrm{eV}) \\
\mathrm{NH}_{2} \mathrm{CH}_{2} \mathrm{CN}+\mathrm{e} \rightarrow \mathrm{CN}^{-}+\mathrm{N}+\mathrm{CH}+\mathrm{H}_{2}+\mathrm{H},(\Delta \mathrm{E}=12.74 \mathrm{eV}) \\
\mathrm{NH}_{2} \mathrm{CH}_{2} \mathrm{CN}+\mathrm{e} \rightarrow \mathrm{CN}^{-}+\mathrm{N}+\mathrm{CH}_{2}+2 \mathrm{H}, & (\Delta \mathrm{E}=12.88 \mathrm{eV})
\end{array}
$$




$$
\mathrm{NH}_{2} \mathrm{CH}_{2} \mathrm{CN}+\mathrm{e} \rightarrow \mathrm{CN}^{-}+\mathrm{N}+\mathrm{C}+4 \mathrm{H} . \quad(\Delta \mathrm{E}=20.74 \mathrm{eV})
$$

All reaction channels are endothermic in the range between $0.99 \mathrm{eV}$ for reaction (1a) up to $20.74 \mathrm{eV}$ for (1o). The appearance energies (AE) derived from the experimental $\mathrm{CN}^{-}$ion yield curve are $1.0 \mathrm{eV}$ for resonance at $1.9 \mathrm{eV}$ and $4.0 \mathrm{eV}$ (resonance at $5.6 \mathrm{eV}$ ), respectively. Based on our calculations of the reaction energy thresholds, the first resonance (at $1.9 \mathrm{eV}$ ) can be assigned to the single AAN bond cleavage reaction channel (1a), with the computed $\Delta \mathrm{E}$ of $0.99 \mathrm{eV}$. In the case of the higher energy resonance (with $\mathrm{AE}$ of $4.0 \mathrm{eV}$ ) in the $\mathrm{CN}^{-}$ion yield, reaction channels (1b) and (1c) may be considered. In reaction (1c) two hydrogen atoms are transferred from the amino group to form methane, which means that a complex molecular rearrangement is required to be involved. Due to the latter and since $\mathrm{CN}^{-}$formation is characterized by the highest ion yield, we investigated this reaction channel computationally in more details. We calculated several local minima and transition states along a reaction path on the potential energy surface connecting the ground state of AAN with the final fragmentation products methane, atomic nitrogen and $\mathrm{CN}^{-}$, see Figure 2. Geometries, harmonic frequencies and zero-point energy corrections have been calculated at the B3LYP/cc-pVTZ+d level of theory, ${ }^{36,37}$ whereas energies have been refined at the CCSD(T)/aug-cc-pVTZ level of theory. ${ }^{37,38}$ Along the considered reaction path, first, a C-N bond is broken upon electron attachment resulting in a neutral $\mathrm{H}_{2} \mathrm{NCH}_{2}$ molecule (Figure 2(c)) and the $\mathrm{CN}^{-}$anion with an energy of about $0.96 \mathrm{eV}$ above the energy of the neutral AAN (Figure 2(b)) in close agreement with the W1BD result of $0.99 \mathrm{eV}$. In a next step, a hydrogen atom is transferred from the amino group in the $\mathrm{H}_{2} \mathrm{NCH}_{2}$ molecule to the $\mathrm{CH}_{2}$ group such that $\mathrm{HNCH}_{3}$ (Figure 2(e)) is formed with an energy of $1.21 \mathrm{eV}$ above the reference energy of the neutral AAN. This proceeds via a transition state (TS1) (Figure 2(d)) which lies $2.81 \mathrm{eV}$ above the reference. In order to form methane and atomic nitrogen, another transition state 
(TS2) has to be passed (Figure 2(f)) with an energy of $4.81 \mathrm{eV}$ above the reference. The latter actually appears too high having in mind the appearance energy of $4.0 \mathrm{eV}$. We note that the accuracy of the used method may be assumed to be rather high (in the order of 2-3 kcal/mol; about $0.08-0.13 \mathrm{eV}$ ) for equilibrium geometries but this cannot be assumed safely also for the transition states though. Therefore, we rather tend to ascribe the second resonance to reaction (1b) with a barrier of $2.81 \mathrm{eV}$. We also observed a broad tail for the second resonance up to the maximum energy considered (about $16 \mathrm{eV}$ ). Hence, other reactions (1c-1n) may be involved in $\mathrm{CN}^{-}$generation at energies above $5.6 \mathrm{eV}$; however, no defined structure can be recognized in the ion signal.

Figure 2. (a) Reaction path connecting the neutral parent molecule AAN with the fragments methane, atomic nitrogen and $\mathrm{CN}^{-}$. Geometries of the local minima and transition states obtained at the B3LYP/cc-pVTZ+d level of theory are shown for (b) neutral AAN, (c) $\mathrm{H}_{2} \mathrm{NCH}_{2}$, (d) transition state TS1, (e) $\mathrm{HNCH}_{3}$, (f) transition state TS2.
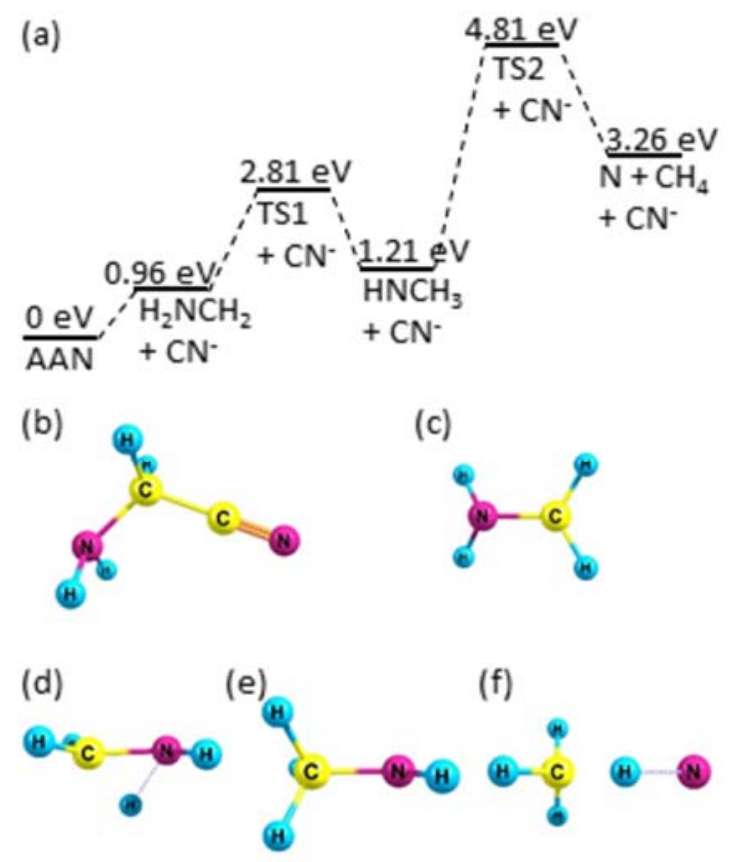
The $\mathrm{NH}_{2}{ }^{-}$ion is the second most efficiently formed anion in the low energy electron interaction with AAN; however, its intensity at peak maximum is $\sim 12$ times lower than for $\mathrm{CN}^{-}$. Beside $\mathrm{CN}^{-}$, it is the second distinctive anion formed by DEA to aminonitriles. ${ }^{5}$ As the EA of $\mathrm{NH}_{2}$ is only $0.77 \mathrm{eV}$ which is significantly lower than the EA of the CN molecule of $3.90 \mathrm{eV}$ (see Table 1), this rather low difference in these two anion intensities additionally support the above explanation of the $\mathrm{CN}^{-}$anion formation route. The negative ion of the amino radical $\left(\mathrm{NH}_{2}\right)$ may be formed via the following reaction channels:

$$
\begin{array}{ll}
\mathrm{NH}_{2} \mathrm{CH}_{2} \mathrm{CN}+\mathrm{e} \rightarrow \mathrm{NH}_{2}{ }^{-}+\mathrm{CH}_{2} \mathrm{CN}, & (\Delta \mathrm{E}=2.63 \mathrm{eV}) \\
\mathrm{NH}_{2} \mathrm{CH}_{2} \mathrm{CN}+\mathrm{e} \rightarrow \mathrm{NH}_{2}{ }^{-}+\mathrm{C}_{2} \mathrm{H}_{2}+\mathrm{N}, & (\Delta \mathrm{E}=7.17 \mathrm{eV}) \\
\mathrm{NH}_{2} \mathrm{CH}_{2} \mathrm{CN}+\mathrm{e} \rightarrow \mathrm{NH}_{2}{ }^{-}+\mathrm{CH}+\mathrm{HCN}, & (\Delta \mathrm{E}=7.40 \mathrm{eV}) \\
\mathrm{NH}_{2} \mathrm{CH}_{2} \mathrm{CN}+\mathrm{e} \rightarrow \mathrm{NH}_{2}{ }^{-}+\mathrm{CH}_{2}+\mathrm{CN}, & (\Delta \mathrm{E}=8.57 \mathrm{eV}) \\
\mathrm{NH}_{2} \mathrm{CH}_{2} \mathrm{CN}+\mathrm{e} \rightarrow \mathrm{NH}_{2}{ }^{-}+\mathrm{C}+\mathrm{H}_{2} \mathrm{CN}, & (\Delta \mathrm{E}=11.13 \mathrm{eV}) \\
\mathrm{NH}_{2} \mathrm{CH}_{2} \mathrm{CN}+\mathrm{e} \rightarrow \mathrm{NH}_{2}{ }^{-}+\mathrm{C}+\mathrm{CN}+\mathrm{H}_{2}, & (\Delta \mathrm{E}=11.93 \mathrm{eV}) \\
\mathrm{NH}_{2} \mathrm{CH}_{2} \mathrm{CN}+\mathrm{e} \rightarrow \mathrm{NH}_{2}{ }^{-}+\mathrm{C}+\mathrm{CN}+2 \mathrm{H}, & (\Delta \mathrm{E}=16.43 \mathrm{eV}) \\
\mathrm{NH}_{2} \mathrm{CH}_{2} \mathrm{CN}+\mathrm{e} \rightarrow \mathrm{NH}_{2}{ }^{-}+2 \mathrm{C}+\mathrm{NH}, & (\Delta \mathrm{E}=16.65 \mathrm{eV}) \\
\mathrm{NH}_{2} \mathrm{CH}_{2} \mathrm{CN}+\mathrm{e} \rightarrow \mathrm{NH}_{2}{ }^{-}+\mathrm{CH}+\mathrm{NH}^{2} \mathrm{C} . & (\Delta \mathrm{E}=17.20 \mathrm{eV})
\end{array}
$$

The amide anion generation occurs in a strong resonance with the appearance energy of $4.7 \mathrm{eV}$ and maximum at $5.6 \mathrm{eV}$. In the ion yield curve, also a second resonance starting at $7.5 \mathrm{eV}$ and peaking at about 9.4 with lower intensity is apparent. Within the observed resonances for the amide anion it can be assumed that its formation is related to the reactions $(2 \mathrm{a}-2 \mathrm{c})$. The calculations yield reaction energy thresholds at $2.63 \mathrm{eV}, 7.17 \mathrm{eV}$, and $7.40 \mathrm{eV}$ for these DEA channels $(2 \mathrm{a}-2 \mathrm{c})$, respectively. Taking this into account, only the first reaction 
(2a) associated with single bond dissociation may be responsible for the formation of $\mathrm{NH}_{2}{ }^{-}$at the main resonance. The formation of the amide anion at the resonance of $9.4 \mathrm{eV}$ may be associated with the DEA channels $(2 b-2 d)$.

\section{$\mathrm{C}_{2} \mathrm{H}_{3} \mathrm{~N}_{2}^{-}$and $\mathrm{C}_{2} \mathrm{H}_{2} \mathrm{~N}_{2}^{-}$}

Similar to earlier studies of electron capture by other nitriles ${ }^{31-33}$ also in the case of AAN, anions formed by the abstraction of one hydrogen atom, $\mathrm{C}_{2} \mathrm{H}_{3} \mathrm{~N}^{-}$, or two hydrogen atoms or a hydrogen molecule, $\mathrm{C}_{2} \mathrm{H}_{2} \mathrm{~N}^{-}$are detected. Positive ions with the same stoichiometry were also observed in the mass spectrum with the $\mathrm{C}_{2} \mathrm{H}_{3} \mathrm{~N}_{2}{ }^{+}$as ones of highest intensity. ${ }^{11,19,20}$ The $\mathrm{C}_{2} \mathrm{H}_{3} \mathrm{~N}_{2}{ }^{-}$anion yield is almost the same as for $\mathrm{NH}_{2}{ }^{-}$one (its yield is of about 14 times lower with respect to $\mathrm{CN}^{-}$).

The $\mathrm{C}_{2} \mathrm{H}_{3} \mathrm{~N}_{2}{ }^{-}$anion may be formed via two channels where the hydrogen atom is abstracted from the methylene or amino group:

$$
\begin{array}{ll}
\mathrm{NH}_{2} \mathrm{CH}_{2} \mathrm{CN}+\mathrm{e} \rightarrow \mathrm{NH}_{2} \mathrm{CHCN}^{-}+\mathrm{H}, & (\Delta \mathrm{E}=2.64 \mathrm{eV}) \\
\mathrm{NH}_{2} \mathrm{CH}_{2} \mathrm{CN}+\mathrm{e} \rightarrow \mathrm{NHCH}_{2} \mathrm{CN}^{-}+\mathrm{H}, & (\Delta \mathrm{E}=2.86 \mathrm{eV})
\end{array}
$$

The experimental data clearly indicate the existence of two possible resonance energies at which the $\mathrm{C}_{2} \mathrm{H}_{3} \mathrm{~N}_{2}{ }^{-}$anion is produced. There are two peaks observed at $3.2 \mathrm{eV}$ and $5.2 \mathrm{eV}$, for which the anion yield at the resonance at lower energy is almost three times larger than at the $5.2 \mathrm{eV}$ maximum. Considering the calculated ground state energies of AAN and fragments involved in reactions ( $3 a$ and $3 b$ ) the energy thresholds for the channels have been derived as $2.64 \mathrm{eV}$ and $2.86 \mathrm{eV}$, respectively. The $(\mathrm{M}-\mathrm{H})^{-}(\mathrm{M}$ denoting the parent molecule) formation efficiency curve provides values of $2.3 \mathrm{eV}$ and $4.3 \mathrm{eV}$ of the experimental $\mathrm{C}_{2} \mathrm{H}_{3} \mathrm{~N}_{2}{ }^{-}$ appearance energies for both resonances detected. Comparing the obtained AEs of anions with the calculated $\Delta \mathrm{Es}$, we notice that the experimental $\mathrm{AE}$ for the low energy resonance is 
slightly lower than the $\Delta \mathrm{E}$ for reaction (3a). If we take into consideration the accuracy of $\mathrm{AE}$ estimation we may affirm that the (3a) reaction is responsible for this resonance. The appearance energy for the second resonance lies above both thermochemical thresholds for the reactions (3a) and (3b). Hence, the $5.2 \mathrm{eV}$ resonance can be attributed to the formation of excited $\mathrm{NH}_{2} \mathrm{CHCN}^{-}$anion via both channels. In the study of positive ionization of AAN the ion at $\mathrm{m} / \mathrm{z}=55(\mathrm{M}-\mathrm{H})$ was attributed to the same fragment structure $\mathrm{NH}_{2} \mathrm{CHCN}^{+}{ }^{11}$

The $\mathrm{C}_{2} \mathrm{H}_{2} \mathrm{~N}_{2}^{-}$ion yield is even lower than that of $\mathrm{C}_{2} \mathrm{H}_{3} \mathrm{~N}_{2}^{-}$. The ion yield ratio for these ions is equal of 0.17 . This significant change in the anion beam intensity may be explained by the number of the $\mathrm{C}-\mathrm{H}$ and $\mathrm{N}-\mathrm{H}$ bonds which have to be broken in order to form the corresponding anions. In case of $\mathrm{C}_{2} \mathrm{H}_{2} \mathrm{~N}_{2}{ }^{-}$two $\mathrm{H}$ atoms must be cleaved from the AAN molecule and therefore the following reaction channels may be considered to explain its formation:

$$
\begin{array}{lc}
\mathrm{NH}_{2} \mathrm{CH}_{2} \mathrm{CN}+\mathrm{e} \rightarrow \mathrm{NHCHCN}^{-}+\mathrm{H}_{2}, & (\Delta \mathrm{E}=0.79 \mathrm{eV}) \\
\mathrm{NH}_{2} \mathrm{CH}_{2} \mathrm{CN}+\mathrm{e} \rightarrow \mathrm{NCH}_{2} \mathrm{CN}^{-}+\mathrm{H}_{2}, & (\Delta \mathrm{E}=0.85 \mathrm{eV}) \\
\mathrm{NH}_{2} \mathrm{CH}_{2} \mathrm{CN}+\mathrm{e} \rightarrow \mathrm{NH}_{2} \mathrm{CCN}^{-}+\mathrm{H}_{2}, & (\Delta \mathrm{E}=1.89 \mathrm{eV}) \\
\mathrm{NH}_{2} \mathrm{CH}_{2} \mathrm{CN}+\mathrm{e} \rightarrow \mathrm{NHCHCN}^{-}+2 \mathrm{H}, & (\Delta \mathrm{E}=5.27 \mathrm{eV}) \\
\mathrm{NH}_{2} \mathrm{CH}_{2} \mathrm{CN}+\mathrm{e} \rightarrow \mathrm{NCH}_{2} \mathrm{CN}^{-}+2 \mathrm{H}, & (\Delta \mathrm{E}=5.34 \mathrm{eV}) \\
\mathrm{NH}_{2} \mathrm{CH}_{2} \mathrm{CN}+\mathrm{e} \rightarrow \mathrm{NH}_{2} \mathrm{CCN}^{-}+2 \mathrm{H} . & (\Delta \mathrm{E}=6.30 \mathrm{eV})
\end{array}
$$

As in the AAN molecule two groups containing $\mathrm{H}$ atoms are present, six (4a-4f) reaction channels can be responsible for $\mathrm{C}_{2} \mathrm{H}_{2} \mathrm{~N}_{2}{ }^{-}$ion formation in three different structures: $\mathrm{NHCHCN}^{-}, \mathrm{NCH}_{2} \mathrm{CN}^{-}$and $\mathrm{NH}_{2} \mathrm{CCN}^{-}$. The total energy balance is in favour of $\mathrm{H}$ atom abstraction from both, amino and methylene groups of AAN. In that case, depending on the neutral fragments formed $\mathrm{H}_{2}(4 \mathrm{a})$ or $2 \mathrm{H}(4 \mathrm{~d})$ the thermodynamic thresholds are equal of 0.79 
$\mathrm{eV}$ and $5.27 \mathrm{eV}$, respectively. Very similar, but a little larger $\Delta \mathrm{Es}$ are calculated for the channels $(4 \mathrm{~b}, 4 \mathrm{e})$ for which both $\mathrm{H}$ atoms are separated from the amino group of AAN. These reaction thresholds are obtained as $0.85 \mathrm{eV}$ and $5.34 \mathrm{eV}$ for the respective channels with generation of neutrals $\mathrm{H}_{2}(4 \mathrm{~b})$ or $2 \mathrm{H}(4 \mathrm{e})$. The highest energy is needed to open the channels of the $\mathrm{C}_{2} \mathrm{H}_{2} \mathrm{~N}_{2}{ }^{-}$formation where the two $\mathrm{C}-\mathrm{H}$ bonds are broken in the methylene group of the AAN molecule. Depending on neutral product $\left(\mathrm{H}_{2}\right.$ or $\left.2 \mathrm{H}\right)$ reactions $(4 \mathrm{c})$ and $(4 \mathrm{f})$ are endothermic by $1.89 \mathrm{eV}$ and $6.30 \mathrm{eV}$, respectively.

The experimental $\mathrm{C}_{2} \mathrm{H}_{2} \mathrm{~N}_{2}^{-}$ion yield shows that the formation of this anion is characterized by a major low energy resonance yielding the $\mathrm{AE}$ of $1.6 \mathrm{eV}$ and the maximum at $2.5 \mathrm{eV}$. Also the second, minor and higher energy resonance with appearance energy of $4.6 \mathrm{eV}$, peaking at $5.2 \mathrm{eV}$ appears in this anion yield curve. These data show that for the $2.5 \mathrm{eV}$ resonance reactions (4a, $4 \mathrm{~b}$ and as well $4 \mathrm{c}$ ) are energetically accessible and hence we can ascribe the first $\mathrm{C}_{2} \mathrm{H}_{2} \mathrm{~N}_{2}{ }^{-}$resonance to these reaction channels. However from the energetic point of view, DEA channels with the lower reaction threshold (4a and $4 \mathrm{~b}$ ) are most probably responsible for formation of $\mathrm{C}_{2} \mathrm{H}_{2} \mathrm{~N}_{2}{ }^{-}$at $2.5 \mathrm{eV}$ resonance. Due to the low difference in the thermochemical energy thresholds $(0.79 \mathrm{eV}$, and $0.85 \mathrm{eV})$ of reaction $4 \mathrm{a}$ and $4 \mathrm{~b}$ it is impossible to clearly state which one from these anion formation routes is most likely responsible for $\mathrm{C}_{2} \mathrm{H}_{2} \mathrm{~N}_{2}{ }^{-}$generation at this energy. The higher energy resonance $(5.2 \mathrm{eV})$ is most probably associated with the channel $(4 \mathrm{c})$ in which the neutral hydrogen molecule is formed by the breaking two single $\mathrm{C}-\mathrm{H}$ bound in the methylene part of the AAN. Additionally, one of the reactions $4 \mathrm{a}$ or $4 \mathrm{~b}$, most probably with the higher $\Delta \mathrm{E}$ may be also responsible for $\left(\mathrm{M}-\mathrm{H}_{2}\right)^{-}$generation. In that case the products of such a DEA reaction will carry on the excess energy $(\mathrm{AE}-\Delta \mathrm{E})$ by molecular excitation or kinetic energy. Based on the above assumptions the $\mathrm{C}_{2} \mathrm{H}_{2} \mathrm{~N}_{2}{ }^{-}$formation is most probably associated with the formation of molecular hydrogen. Mass spectrometric studies of $\mathrm{Ni}^{+}$ions reacting with AAN 
in the gas phase have shown that the loss of $\mathrm{H}_{2}$ molecule from AAN is also a very effective process in the case of positive ion formation. ${ }^{39}$

\section{$\mathrm{C}_{2} \mathrm{H}_{2} \mathrm{~N}^{-}$and $\mathrm{C}_{2} \mathrm{HN}^{-}$}

The $\mathrm{C}_{2} \mathrm{H}_{2} \mathrm{~N}^{-}$and $\mathrm{C}_{2} \mathrm{HN}^{-}$anions were also detected in the present studies of DEA to AAN. Concerning these anions, the DEA process includes the loss of one nitrogen atom from the neutral parent molecule and simultaneous bond breaking associated with two or three hydrogen atoms.

The reactions leading to $\mathrm{C}_{2} \mathrm{H}_{2} \mathrm{~N}^{-}$anion formation read as follows:

$$
\begin{array}{ll}
\mathrm{NH}_{2} \mathrm{CH}_{2} \mathrm{CN}+\mathrm{e} \rightarrow \mathrm{C}_{2} \mathrm{H}_{2} \mathrm{~N}^{-}+\mathrm{NH}_{2}, & (\Delta \mathrm{E}=1.84 \mathrm{eV}) \\
\mathrm{NH}_{2} \mathrm{CH}_{2} \mathrm{CN}+\mathrm{e} \rightarrow \mathrm{C}_{2} \mathrm{H}_{2} \mathrm{~N}^{-}+\mathrm{N}+\mathrm{H}_{2}, & (\Delta \mathrm{E}=4.80 \mathrm{eV}) \\
\mathrm{NH}_{2} \mathrm{CH}_{2} \mathrm{CN}+\mathrm{e} \rightarrow \mathrm{C}_{2} \mathrm{H}_{2} \mathrm{~N}^{-}+\mathrm{NH}+\mathrm{H}, & (\Delta \mathrm{E}=5.88 \mathrm{eV}) \\
\mathrm{NH}_{2} \mathrm{CH}_{2} \mathrm{CN}+\mathrm{e} \rightarrow \mathrm{C}_{2} \mathrm{H}_{2} \mathrm{~N}^{-}+\mathrm{N}+2 \mathrm{H} . & (\Delta \mathrm{E}=9.30 \mathrm{eV})
\end{array}
$$

The intensity of the anion yield for $\mathrm{C}_{2} \mathrm{H}_{2} \mathrm{~N}^{-}$is $\sim 33$ times lower than that of $\mathrm{CN}^{-}$, placing $\mathrm{C}_{2} \mathrm{H}_{2} \mathrm{~N}^{-}$in fourth position of generated anions from AAN. The measured $\mathrm{C}_{2} \mathrm{H}_{2} \mathrm{~N}^{-}$ signal shows that this anion is formed within a broad energy region between about 0.5 to 17 $\mathrm{eV}$. We recognize one major resonance at $5.4 \mathrm{eV}$. Additionally, closer inspection in this anion yield indicates further low intensity resonances: two at low and one at high energy regions above $10 \mathrm{eV}$. In the 0.5 to $4 \mathrm{eV}$ regime there are observable resonances at about $2.0 \mathrm{eV}$ and $2.9 \mathrm{eV}$, whereas at higher electron energy we can distinguish also a resonance with maximum of $\sim 10.8 \mathrm{eV}$. Moreover, a very low anion signal is observed at energies from $13 \mathrm{eV}$ to $17 \mathrm{eV}$. The resonance at low energy appeared at $0.1 \mathrm{eV}$ which is definitely below all calculated reaction thresholds. Therefore, this low intensity anion signal most probably corresponds to the DEA process to some impurity leading to the formation of anion yield at the same 
nominal mass like $\mathrm{C}_{2} \mathrm{H}_{2} \mathrm{~N}^{-}$. The main resonance has the appearance energy of $4.3 \mathrm{eV}$. Within the calculated thermochemical thresholds, the $5.4 \mathrm{eV}$ resonance may be attributed to reaction (5a) with $\Delta \mathrm{E}$ of $1.84 \mathrm{eV}$. The reaction (5a) is complementary to the channel (2a) describing the $\mathrm{NH}_{2}^{-}$anion formation. The shapes of both resonances (2a and 5a) are different. In particular, the signal of $\mathrm{C}_{2} \mathrm{H}_{2} \mathrm{~N}^{-}$decreases more gradually than $\mathrm{NH}_{2}^{-}$. This may be an indication that in the former case other resonances can be involved. However, considering the AEs and $\triangle E$ s for both (2a and 5a) DEA channels it may be concluded that they are characterised by the high excess energy of $\sim 2 \mathrm{eV}$. This energy excess may also be used for the further decomposition of the anion formed. Such decomposition promotes rather bigger than smaller fragments changing also the shape of its anion yield, like in our case. The existence of the higher energy resonance $(10.8 \mathrm{eV})$ would correspond to the occurrence of $\mathrm{C}_{2} \mathrm{H}_{2} \mathrm{~N}^{-}$anion formation via reactions ( $5 \mathrm{~b}$ and $5 \mathrm{c}$ ) with the thermochemical thresholds of 4.8 and $5.88 \mathrm{eV}$, respectively. The measured signal at energies above $13 \mathrm{eV}$ may be also related to the channel (5d) with the calculated threshold of $9.30 \mathrm{eV}$, where all neutral fragments generated are in atomic form.

The $\mathrm{C}_{2} \mathrm{HN}^{-}$anion has the lowest intensity of all anions formed by DEA to AAN. The yield is about a factor 1000 times lower than the $\mathrm{CN}^{-}$yield. The possible DEA channels at which $\mathrm{C}_{2} \mathrm{HN}^{-}$is formed are:

$$
\begin{array}{ll}
\mathrm{NH}_{2} \mathrm{CH}_{2} \mathrm{CN}+\mathrm{e} \rightarrow \mathrm{C}_{2} \mathrm{HN}^{-}+\mathrm{NH}_{3}, & (\Delta \mathrm{E}=1.25 \mathrm{eV}) \\
\mathrm{NH}_{2} \mathrm{CH}_{2} \mathrm{CN}+\mathrm{e} \rightarrow \mathrm{C}_{2} \mathrm{HN}^{-}+\mathrm{NH}+\mathrm{H}_{2}, & (\Delta \mathrm{E}=5.44 \mathrm{eV}) \\
\mathrm{NH}_{2} \mathrm{CH}_{2} \mathrm{CN}+\mathrm{e} \rightarrow \mathrm{C}_{2} \mathrm{HN}^{-}+\mathrm{NH}_{2}+\mathrm{H}, & (\Delta \mathrm{E}=5.90 \mathrm{eV}) \\
\mathrm{NH}_{2} \mathrm{CH}_{2} \mathrm{CN}+\mathrm{e} \rightarrow \mathrm{C}_{2} \mathrm{HN}^{-}+\mathrm{N}+\mathrm{H}+\mathrm{H}_{2}, & (\Delta \mathrm{E}=8.86 \mathrm{eV}) \\
\mathrm{NH}_{2} \mathrm{CH}_{2} \mathrm{CN}+\mathrm{e} \rightarrow \mathrm{C}_{2} \mathrm{HN}^{-}+\mathrm{NH}+2 \mathrm{H}, & (\Delta \mathrm{E}=9.95 \mathrm{eV}) \\
\mathrm{NH}_{2} \mathrm{CH}_{2} \mathrm{CN}+\mathrm{e} \rightarrow \mathrm{C}_{2} \mathrm{HN}^{-}+\mathrm{N}+3 \mathrm{H} . & (\Delta \mathrm{E}=13.37 \mathrm{eV})
\end{array}
$$


The measured $\mathrm{C}_{2} \mathrm{HN}^{-}$anion signal shows that this anion is formed within a broad energy region between about 0 to $17 \mathrm{eV}$ with five resonances at $1.3 \mathrm{eV}, 2.4 \mathrm{eV}, 5.6 \mathrm{eV}, 8.3$ $\mathrm{eV}$ and $10.8 \mathrm{eV}$, and with a long tail up to about $17 \mathrm{eV}$. The plurality of resonance features leading to the $\mathrm{C}_{2} \mathrm{HN}^{-}$anion generation ratifies that this ion formation proceeds also via electron attachment to different states of the electronically excited molecule. In $\mathrm{C}_{2} \mathrm{HN}^{-}$anion formation, where additional energy in comparison to $\mathrm{C}_{2} \mathrm{H}_{2} \mathrm{~N}^{-}$formation is needed for the $\mathrm{H}$ atom separation, we, surprisingly, obtained an ion signal at $\mathrm{m} / \mathrm{z}=39$ in the low electron energy region from about 0 to $4 \mathrm{eV}$. The lowest threshold energy for $\mathrm{C}_{2} \mathrm{HN}^{-}$formation via reaction (6a) is $1.25 \mathrm{eV}$ and hence considerably above the ion yield observed experimentally. Hence, we ascribe the ion yield observed in the region between 0 to $4 \mathrm{eV}$ rather to an impurity. The third recognized resonance (at $5.6 \mathrm{eV}$ ) has the appearance energy of $4.2 \mathrm{eV}$, therefore it may be associated with the reaction (6a) where the neutral ammonia molecule is formed in addition to the $\mathrm{C}_{2} \mathrm{HN}^{-}$anion. The highest signal intensity was measured for the resonance at $8.3 \mathrm{eV}$ with the experimental appearance energy of $6.0 \mathrm{eV}$. By comparison with the calculations we ascribe the $8.3 \mathrm{eV}$ peak to the (6b and 6c) DEA channels. Due to the electron beam energy resolution, clear evidence which of these reactions is responsible or dominant is impossible. In relation to the number of the bonds needed to be broken in the AAN molecule the reaction (6b) is less probable than (6c). In DEA channel (6b), 3 bonds have to be broken and additionally one hydrogen molecule has to be generated, whereas in the reaction (6c) only 2 bonds are disrupted. In case of the resonance with the maximum at about $10.8 \mathrm{eV}$ and the appearance energy of $9.0 \mathrm{eV}$ the reaction $(6 \mathrm{~d})$ with the thermodynamical threshold of $8.86 \mathrm{eV}$ may be involved. The low anion signal above $10.8 \mathrm{eV}$ peak may indicate that also the remaining channels may play some role in this anion generation.

\section{CONCLUSIONS}


Dissociative electron attachment to aminoacetonitrile (AAN), an important astrophysical compound, was studied in the gas phase using electron attachment spectroscopy. The present study has shown that six anionic species are formed via DEA to AAN in the electron energy range of about $0 \mathrm{eV}$ to $17 \mathrm{eV}$. For all possible anion fragments the DEA routes leading to the formation of respective negative ions are provided and thermochemical thresholds are calculated. Similarly to the earlier studies of other aminonitriles, also in the case of $\mathrm{NH}_{2} \mathrm{CH}_{2} \mathrm{CN}$ the $\mathrm{CN}^{-}, \mathrm{NH}_{2}^{-}$and $(\mathrm{M}-\mathrm{H})^{-}$are the most abundant fragment anions measured. The respective anion signals intensities are rather low, indicating a resistivity of AAN to electron capture induced dissociation and probably a long half-life time in space-like environments. AAN is suspected to be of significant relevance in the formation process of amino acids in the ISM. Therefore, we think that our investigation, in which AAN is irradiated with low energy electrons, is important also for a deeper understanding of such processes in the ISM.

\section{Acknowledgements}

This work was partially supported by the Polish National Science Centre, grant no. 2013/11/B/ST10/00250, and the Austrian Science Fund (FWF I1015).

\section{References}

(1) Alizadeh, E.; Orlando, T.M; Sanche, L. Biomolecular damage induced by ionizing radiation: the direct and indirect effects of low-energy electrons on DNA. Ann. Rev. Phys.

Chem. 2015, 66, 379-398. 
(2) Tanzer, K.; Feketeova, L.; Puschnigg, P.; Scheier, P.; Illenberger, E. Denifl, S. Reactions in nitroimidazole triggered by low-energy ( $0-2 \mathrm{ev})$ electrons: Methylation at N1-H completely blocks reactivity. Angew. Chem.-Int. Ed. 2014, 53, 12240-12243.

(3) Baccarelli, I.; Bald, I.; Gianturco, F.A.; Illenberger, E.; Kopyra, J. Electron-induced damage of DNA and its components: Experiments and theoretical models. Phys. Rep. 2011, $508,1-44$.

(4) Neustetter, M.; Aysina, J.; Ferreira da Silva, F.;_Denifl, S. The effect of solvation on electron attachment to pure and hydrated pyrimidine clusters. Angew. Chem.-Int. Ed. 2015, $54,9124-9126$.

(5) Tanzer, K.; Pelc, A.; Huber, S.E.; Czupyt, Z.; Denifl, S. Low energy electron attachment to cyanamide (NH2CN). J. Chem. Phys. 2015, 142, 034301.

(6) Danger, G.; Borget, F.; Chomat, M.; Duvernay, F.; Theule, P.; Guillemin, J.-C.; Le Sergeant d'Hendecourt, L.; Chiavassa, T. Experimental investigation of aminoacetonitrile formation through the Strecker synthesis in astrophysical-like conditions: reactivity of methanimine $(\mathrm{CH} 2 \mathrm{NH})$, ammonia $(\mathrm{NH} 3)$, and hydrogen cyanide $(\mathrm{HCN})$. Astronomy \& Astrophysics 2011, 535, A47.

(7) He, C.; Smith, M.A. Identification of nitrogenous organic species in Titan aerosols analogs: Implication for prebiotic chemistry on Titan and early Earth. Icarus 2014, 238, 8692.

(8) Lerner, N.R.; Cooper, G.W. Iminodicarboxylic acids in the Murchison meteorite:

Evidence of Strecker reactions. Geoch. Cosm. Acta 2005, 69, 2901-2906.

(9) Strecker, A.; Ueber einen neuen aus Aldehyd - Ammoniak und Blausäure entstehenden Körper. Annalen der Chemie und Pharmazie 1854, 91, 349-351.

(10) Stahler, S.W.; The cyanopolyynes as a chemical clock for molecular clouds. Astrophys. Journal 1984, 281, 209-218. 
(11) Danger, G.; Bossa, J.-B.; de Marcellus, P.; Borget, F.; Duvernay, F.; Theule, P.;

Chiavassa, T.; d'Hendecourt, L. Experimental investigation of nitrile formation from VUV photochemistry of interstellar ices analogs: acetonitrile and amino acetonitrile. Astronomy \& Astrophysics 2011, 525, A30.

(12) Belloche, A.; Menten, K.M.; Comito, C. Detection of amino acetonitrile in Sgr B2(N). Astronomy \& Astrophysics 2008, 482, 179-196.

(13) Liebman, S.A.; Pesce-Rodrigez, R.A.; Matthews, C.N. Organic analysis of hydrogen cyanide polymers: prebiotic and extraterrestrial chemistry. Adv. Space Res. 1995, 15, 71-80. (14) Bernstein, M.; Ashbourn, S.F.M.; Sandford, S.A.; Allamandola, L.J. The lifetimes of nitriles $(\mathrm{CN})$ and acids $(\mathrm{COOH})$ during ultraviolet photolysis and their survival in space. Astrophys. J. 2004, 601, 365-370.

(15) Igamberdiev, A.U.; Bykowa, N.V.; Gardeström, P. Involvement of cyanide-resistant and rotenone-insensitive pathways of mitochondrial electron transport during oxidation of glycine in higher plants. FEBS Lett. 1997, 412, 265-269.

(16) Chastain, C.J.; Ogren, W.L. Photorespiration-induced reduction of ribulose bisphosphate carboxylase activation level. Plant Physiol. 1985, 77, 851-856.

(17) Créach, E.; Stewart, C.R. Effects of aminoacetonitrile on net photosynthesis, ribulose1,5-bisphosphate levels, and glycolate pathway intermediates. Plant Physiol. 1982, 70, 14441448.

(18) Yin, Z.; Zhang, Z.; Zhu, J.; Wong, H.; Kadow, J.F.; Meanwell, N.A.; Wang, T. Synthesis of substituted aryl amidines from aminoacetonitriles. Tetrahedr. Lett. 2005, 46, 4919-4923.

(19) Borget,F.; Danger, G.; Duvernay, F.; Chomat, M.; Vinogrtadoff, V.; Theule, P.; Chiavassa, T. Aminoacetonitrile characterization in astrophysical-like conditions. Astronomy \& Astrophysics 2012, 541, A114. 
(20) NIST Chemistry Webbook. Available from: http://webbook.nist.gov/chemistry.

(21) Alizadeh, E.; Ferreira da Silva, F.; Zappa, F.; Mauracher, A.; Probst, M.; Denifl, S.; Bacher, A.; Märk, T.D.; Limão-Vieira, P.; Scheier, P. Dissociative electron attachment to nitromethane. Int. J. Mass Spect. 2008, 271, 15-21.

(22) Hotop, H.; Ruf, M.-W.; Allan, M; Fabrikant, I.I. Resonance and threshold phenomena in low-energy electron collisions with molecules and clusters. Adv. At. Mol. Opt. Phys. 2003, 49, $85-216$

(23) Matejcik, S.; Kiendler, A.; Stamatovic, A.; and Märk, T.D. A crossed-beam highresolution study of dissociative electron-attachment to CCl4. Int. J. Mass Spectrom. Ion Proc. 1995, 149/150, 311-319.

(24) Braun, M.; Marienfeld, S.; Ruf, M.-W.; Hotop, H. High-resolution electron attachment to the molecules CCl4 and SF6 over extended energy ranges with the (EX)LPA method. J. Phys. B 2009, 42, 125202.

(25) Barnes, E.C.; Petersson, G.A.; Montgomery Jr., J.A.; Frisch, M.J.; Martin, J.M.L.

Unrestricted coupled cluster and brueckner doubles variations of W1 theory. J. Chem. Theor. Comput. 2009, 5, 2687-2693.

(26) Curtiss, L.A.; Raghavachari, K.; Redfern, P.C.; Pople, J.A. Assessment of Gaussian-2 and density functional theories for the computation of enthalpies of formation. J. Chem. Phys. 1997, 106, 1063-1079.

(27) Curtiss, L.A.; Redfern, P.C.; Raghavachari, K.; Pople, J.A. Assessment of Gaussian-2 and density functional theories for the computation of ionization potentials and electron affinities. J. Chem. Phys. 1998, 109, 42-55

(28) Frisch, M.J.; Trucks, G.W.; Schlegel, H.B.; Scuseria, G.E.; Robb, M.A.; Cheeseman, J.R.; Scalmani, G.; Barone, V.; Mennucci, B.; Petersson, G.A. et al. Gaussian 09, Revision C.01, Gaussian, Inc., Wallingford CT, 2009. 
(29) Naganathappa, M.; Chaudhari, A. Spectroscopic characterization of aminoacetonitrile, its ions and protonated aminoacetonitrile using quantum chemical methods. Int. J. Quant. Chem. 2011, 111, 2064-2071.

(30) Agúndez, M.; Cernicharo, J.; Guélin, M.; Kahane, C.; Roue, E.; Kłos, J.; Aoiz, F.J.; Lique, F.; Marcelino, N.; Goicoechea, J.R.; González García, M.; Gottlieb, C.A.; McCarthy, M.C.; Thaddeus, P. Astronomical identification of CN-, the smallest observed molecular anion. Astronomy \& Astrophysics 2010, 517, L2.

(31) Sailer, W.; Pelc, A.; Limao-Vieira, P.; Mason, N.J.; Limtrakul, J.; Scheier, P.; Probst, M.; Märk, T.D. Low energy electron attachment to CH3CN. Chem. Phys. Lett. 2003, 381, $216-222$

(32) Heni, M.; Illenberger, E. The isomers CF3NC and CF3CN - formation and dissociation of the anions formed on electron-attachment. Int. J. Mass Spectrom. Ion Proc. 1986, 71, 199210.

(33) Heni, M.; Illenberger, E. Electron-attachment by saturated nitriles, acrylonitrile (C2H3CN), and benzonitrile (C6H5CN). Int. J. Mass Spectrom. Ion Proc. 1986, 73, 127-144. (34) Chaban, G.M. Anharmonic vibrational spectroscopy of nitriles and their complexes with water. J. Phys. Chem. A 2004, 108, 4551-4556.

(35) Bernstein, M.P.; Bauschlicher Jr, C.W.; Sandford, S.A. The infrared spectrum of matrix isolated aminoacetonitrile, a precursor to the amino acid glycine. Adv. Space Res. 2004, 33, $40-43$

(36) Becke, A.D. Density-functional thermochemistry. III. The role of exact exchange. $J$. Chem. Phys. 1993, 98, 5648-52.

(37). Dunning Jr., T. H. Gaussian basis sets for use in correlated molecular calculations. I. The atoms boron through neon and hydrogen. J. Chem. Phys. 1989, 90, 1007-23. 
(38) Pople, J. A.; Head-Gordon, M. and Raghavachari, K. Quadratic configuration interaction

- a general technique for determining electron correlation energies. J. Chem. Phys. 1987, 87, $5968-75$.

(39) Lamsabhi, A.M.; Mo, O.; Yanez, M.; Guillemin, J.-C.; Haldys, V.; Tortajada, J.; Salpin, J.-Y. Ni+ reactions with aminoacetonitrile, a potential prebiological precursor of glycine. $J$. Mass Spectrom. 2008, 43, 317-326. 